\title{
An Empirical Evaluation of GARCH Models in Value-at-Risk Estimation: Evidence from the Macedonian Stock Exchange

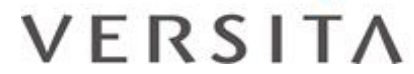

\author{
Vesna Bucevska
}

\author{
Faculty of Economics, University "Ss. Cyril and Methodius", Skopje, Republic of Macedonia
}

\begin{abstract}
Background: In light of the latest global financial crisis and the ongoing sovereign debt crisis, accurate measuring of market losses has become a very current issue. One of the most popular risk measures is Value-at-Risk (VaR). Objectives: Our paper has two main purposes. The first is to test the relative performance of selected GARCH-type models in terms of their ability of delivering volatility estimates. The second one is to contribute to extend the very scarce empirical research on VaR estimation in emerging financial markets. Methods/Approach: Using the daily returns of the Macedonian stock exchange index-MBI 10, we have tested the performance of the symmetric GARCH $(1,1)$ and the GARCH-M model as well as of the asymmetric EGARCH $(1,1)$ model, the GARCH-GJR model and the APARCH $(1,1)$ model with different residual distributions. Results: The most adequate GARCH family models for estimating volatility in the Macedonian stock market are the asymmetric EGARCH model with Student's t-distribution, the EGARCH model with normal distribution and the GARCH-GJR model. Conclusion: The econometric estimation of VaR is related to the chosen GARCH model. The obtained findings bear important implications regarding VaR estimation in turbulent times that have to be addressed by investors in emerging capital markets.

Keywords: Value-at-Risk, GARCH models, forecasting volatility, financial crisis, Macedonia JEL classification: C22, C52, C53, C58, G10

Paper type: Research article
\end{abstract}

Received: 21, September, 2012

Revised: 29, November, 2012

Accepted: 24, December, 2012

Citation: Bucevska, V. (2012). "An Empirical Evaluation of GARCH Models in Value-at-Risk Estimation: Evidence from the Macedonian Stock Exchange", Business Systems Research, Vol. 4, No. 1, pp. 49-64.

DOI: $10.2478 /$ bsrj-2013-0005

\section{Introduction}

The impetus for Value-at-Risk (VaR), the most well-known financial risk measurement, came from failures of financial institutions and the responses of regulators to these failures. Following the increase in financial instability in the beginning of the 70's years as a result of the advent of derivative markets and floating exchange rates, several methods of risk measurement have been developed. However, VaR is the most popular one.

Value-at-Risk (VaR) is defined as the worst loss over a target horizon with a given level of confidence (Jorion, 2007). The first regulatory measures that evoke Value-at- Risk, were initiated in the 80s, when the Securities Exchange Commission (SEC) tied the capital requirements of financial service firms to the losses that would be incurred, with $95 \%$ confidence over a thirty-day interval, in different security classes. In parallel with that, the trading portfolios of financial institutions were becoming larger and more volatile, creating a need for more sophisticated and timely risk measurement. By the early 90s, many banks have developed different rudimentary measures of Value-at-Risk. As a consequence of the big financial disasters that occurred between 1993 and 1995, there was a growing need for a response to those market losses by banks and other financial institutions, central bankers and academics in terms of building accurate models for measuring market risk. The popularity of VaR and the debate over the validity of the underlying statistical assumptions increased since 
1994, when JP Morgan made available to its Risk Metrics methodology through the Internet. The free accessibility of the Risk Metrics triggered academics and practitioners to find the best-performing market risk quantification method.

The importance of risk measurement and estimation and prediction of market losses has significantly increased during the 2007-08 global financial crisis. It is not a long time since the world financial system is recovering from its latest and severest financial crisis that we are again dealing with a new one - the Europe's sovereign-debt crisis. In the light of the ongoing crisis in the Euro zone, accurate measuring and forecasting of market losses seems to play a crucial role both in developed and emerging financial markets.

Unlike the financial markets of developed countries, the emerging financial markets are characterized with insufficient liquidity, the small scale of trading and asymmetrical and low number of trading days with certain securities (Andjelić, Djaković and Radišić, 2010). The emerging stock markets as relatively young markets are not sufficiently developed to identify all information which affects the stock prices and therefore, does not respond quickly to the publicly disclosed information (Benaković and Posedel, 2010). In their study of 16 emerging markets in Europe, Latin America and Asia Dimitrakopoulos, Kavussanos and Spyrou (2010) point out that average daily returns are not significantly different from zero for the emerging markets. Their return volatilities are twice the volatilities of developed markets (Dimitrakopoulos et al., 2010). Furthermore, return series exhibit significant positive or negative skewness coefficients (Dimitrakopoulos et al., 2010). Emerging market's kurtosis values are on average higher than those of developed markets suggesting fatter tailed distributions (Dimitrakopoulos et al., 2010). Batten and Szilagyi (2011) point out that emerging stock market volatility is characterized by a complex dynamics, mainly during crises and turbulent periods. The above-described differences between the developed and emerging financial markets, the growing interest of foreign financial investors to invest in emerging financial markets and the increased financial fragility in these markets, highlight the importance of accurate market risk quantification and prediction.

The purpose of this paper is to test the relative performance of a range of symmetric and asymmetric GARCH family models in estimating and forecasting Value-at-Risk in the Macedonian stock exchange over a long sample period which includes tranquil as well as stress years.

As an EU candidate country with a high potential for stock market growth, Macedonia is an interesting destination for foreign financial investors, who, due to the distinctions between developed and emerging financial markets and the turbulent market environment, need to test the possibility to apply GARCH models in VaR estimation and forecasting in the Macedonian stock market.

Our empirical results indicate that the most adequate GARCH family models for estimating and forecasting volatility in the Macedonian stock market are the asymmetric EGARCH model with Student's t-distribution, the EGARCH model with normal distribution and the GARCH-GJR model which are robust with regard to the estimation.

The rest upon the paper is organized as follows. In Section 2 we give a brief literature review. In Section 3 we describe the symmetric and asymmetric GARCH family models used throughout our study. Section 4 presents the data used and the results of the preliminary analysis. In Section 5 we present our empirical results and in Section 6 we discuss the obtained results and draw conclusions.

\section{Literature review}

VaR models were created and tested in the developed financial markets for measuring market risks.

Despite the extensive literature and empirical research of estimation of VaR models in the major developed financial markets, literature dealing with VaR calculation in emerging financial market is very scarce (Hagerud, 1997; Gokcan, 2000; Brooks and Persand, 2000; Magnussson and Andonov, 2002; Da Silva, Beatriz and de Melo Mendes, 2003; Parrondo, 1997; Valentinyi-Enrdesz, 2004; Bao, Lee and Saltoglu, 2006; Zikovic and Bezic, 2006; McMillan and Speght, 2007; Kovacic, 2007; Zikovic and Aktan, 2009; Zikovic and Filler, 2009; Andjelic et al., 2010). The main reason for that was the short historical time-series data (most of the stock markets in these countries were established in the early nineties) which did not allow performing a reliable econometric analysis. 
The situation is even worse as far as the Macedonian stock exchange is concerned. Namely, there is only one empirical study (Kovacic, 2007), to the best of our knowledge, which applies the same methodology as in our paper to estimate and forecast the volatility in the Macedonian stock exchange. However, one of the shortcomings of this study is the short time series return data, which does not allow precise estimation of VaR.

Another limitation of the existing empirical studies on VaR estimation and forecasting in emerging stock market is that only a few of them have tried to consider the effect of a financial crisis on Value-at Risk (VaR) estimation. Namely, Zikovic and Aktan (2009) investigate the relative performance of a wide array of VaR models with the daily returns of Turkish (XU100) and Croatian (Crobex) stock index prior to and during the global 2008 financial crisis. Zikovic and Filler (2009) test the relative performance of VAR and ES models using daily returns for sixteen stock market indices (eight from developed and eight from emerging markets) prior to and during the 2008 financial crisis. However, the main limitation of their studies is the fact that they have tested the relative performances of VaR models at the very beginning of the global financial crisis. Due to the short sample period, their results should be taken with caution and future research with the inclusion of a longer period is needed in order to obtain estimates with greater precision.

Our paper tries to extend the limited empirical research on VaR estimation and forecasting in emerging financial markets and to overcome the above stated limitations of the previous empirical studies by testing the relative performance of a number of symmetric and asymmetric GARCH family models in the estimation of the Macedonian stock exchange volatility.

The theoretical contribution of our study is that it is the first study, to the best of our knowledge, on VaR estimation and forecasting in the Macedonian stock market over a long sample period (from the $4^{\text {th }}$ January 2005 to the $31^{\text {st }}$ October 2011), which includes stable as well as turbulent years (the years of the latest global financial crisis and the ongoing Europe's sovereign-debt crisis).

\section{Methodology}

\section{Symmetric GARCH models}

Accurate volatility estimates are essential for producing robust VaR estimates. In this context, different methods were developed to estimate volatility. The traditional methods of measuring volatility (variance or standard deviation) are unconditional and cannot capture the characteristics of financial time-series data, such as, changing volatility, clustering, asymmetry, leverage effect and long memory properties (Angelidis and Degiannakis, 2005). One of the most accepted models that captures the above patterns of volatility has proven to be the Generalized Autoregressive Conditional Heteroskedasticity (GARCH) models. In this paper, we are focusing upon the use of selected GARCH models to estimate and forecast daily $\mathrm{VaR}$ of the Macedonian stock exchange in turbulent times.

With model volatility of financial time series, Engle (1982) introduced the Autoregressive Conditional Heteroscedasticity (ARCH) model. The general form of the ARCH (q) model is as follows:

$\sigma_{t}^{2}=\alpha+\sum_{i=1}^{q} \beta_{i} \varepsilon_{t-i}^{2}$

where $\sigma^{2}{ }_{t}$ is the conditional variance, and $\varepsilon_{t}$ is the error term. For the conditional variance to be positive, the parameters $\alpha$ and $\beta$ should be greater than zero since standard deviation and variance must be nonnegative and $\beta$ should be less than one in order for the process to be stationary (Angabini and Wasiuzzaman, 2011). In the ARCH (q) model today's expected volatility depends on the squared forecast errors of the previous days (Balaban, 2002).

In many applications of the $\mathrm{ARCH}$ model the required length of the lag, q might be very large (Bollerslev, Chou and Kroner, 1992). In order to overcome this limitation to the ARCH model, Bollerslev, et al. (1992) extended the ARCH model to have a more flexible lag 
structure and a longer memory by adding a lagged conditional variance for the model as well. The model that they proposed was called Generalized Autoregressive Conditional Heteroskedasticity (GARCH) model (Bollerslev et al., 1992).

The GARCH $(p, q)$ model permits a more persistent volatility which is typical for most stock data (Angabini and Wasiuzzaman, 2011). This model allows the conditional variance to be dependent on its previous lagged values. The general form of the $\mathrm{GARCH}(p, q)$ model is given by:

$R_{t}=\mu+\varepsilon_{t}$

$\sigma_{t}^{2}=\omega+\sum_{i=1}^{q} \alpha_{i} \varepsilon_{t-i}^{2}+\sum_{j=1}^{p} \beta_{j} \sigma_{t-j}^{2}$

where $p$ is the order of GARCH and $q$ is the order of $\mathrm{ARCH}$ process, $R_{t}$ are returns of the financial time series (stock exchange index) at time $t$ in natural log (logs), $\mu$ are mean value of the returns; $\varepsilon+$ is the error term at time $t$ which is assumed to be normally distributed with zero mean and conditional variance $\sigma_{t}^{2}$, and $\mu, \omega, \alpha_{i}, \beta_{j}$ are parameters. All parameters in variance equation must be positive. We expect the value of $\omega$ to be small. Parameter $\alpha_{i}$ is the measure of volatility response to movements in the market and parameter $\beta_{j}$ expresses how persistent shocks are that were caused by extreme values of conditional variance. We expect the sum of $\alpha+\beta<1$.

Thanks to the high degree of persistence typically found when estimating GARCH model, this model can account for the characteristics of financial time-series data (fat tails, volatility clusters of returns, etc.). It expresses the conditional variance as a linear function of past information allowing the conditional heteroskedasticity of returns (Curto, Pinto and Tavares, 2009).

According to Brooks (2008), the lag order $(1,1)$ model is sufficient to capture all the volatility clustering in the data. In most empirical applications (French, Schwert and Stambaugh, 1987; Pagan and Schwert, 1990; Franses and Van Dijk, 1996 and Gokcan, 2000), the basic GARCH $(1,1)$ model fits the changing conditional variance of the majority of financial time series reasonably well. The first notation of $(1,1)$ shows ARCH effect and the second one moving average.

The GARCH $(1,1)$ model is given by the following equation:

$\sigma_{t}^{2}=\omega+\alpha_{1} \varepsilon_{t-1}^{2}+\beta_{1} \sigma_{t-1}^{2}(3)$

To guarantee a positive variance at all instances, it is imposed that $\omega>0$ and that $\alpha, \beta \geq 0$.

Engle, Lilien and Robins (1987) extended the GARCH model to GARCH-in-Mean (GARCH-M) model which allows the conditional mean to be a function of conditional variance. The GARCH-M model is given by:

$R_{t}=\mu+\beta_{2} \sigma_{t}^{2}+\varepsilon_{t}$

$\varepsilon_{t} \sim N\left(0, \sigma_{t}^{2}\right)$

$\sigma_{t}^{2}=\omega+\alpha \varepsilon_{t-i}^{2}+\beta_{1} \sigma_{t-1}^{2}$

In order to ensure that the conditional variance, $\sigma_{t}^{2}$ is positive, we must impose the nonnegativity constraint on the coefficients in the above equation. In GARCH-M $(1,1)$ as the sum of the coefficients approaches unity, the persistence of shocks to volatility is greater. However, volatility could have a significant impact on the stock returns only if these shocks 
are permanent over a longer period of time. The GARCH-M model also implies that there are serial correlations between return series (Hien, 2008).

\section{Asymmetric GARCH models}

The above-described GARCH-type models consider negative and positive error terms to have symmetric effects on volatility, i.e. that negative and positive shocks have the same effect on volatility. However, there is a large literature documenting that the sign of the shock does matter (Black, 1976; Christie, 1982; French et al., 1987; Schwert, 1990; Nelson, 1991; Campbell and Hentschel, 1992; Cheung and Ng, 1993; Glosten, Jagannathan and Runkle, 1993; Bae and Karolyi, 1994; Braun, Nelson and Sunier, 1995; Duffee, 1995; Bekaert and Harvey, 1997; Ng, 2000; Bekaert and Guojun, 2000, etc.). A general finding across these studies is that negative returns tend to be followed by periods of greater volatility than positive returns of equal size. In other words, bad news tends to increase volatility more than good news (Angabini and Wasiuzzaman, 2011). An explanation for the asymmetric response of return volatility to the sign of the shock is that positive and negative shocks lead to different values of a firm's financial leverage (its debt-to-equity ratio), which in turn will result in different volatilities (Black, 1976). The term leverage stems from the empirical observation that the conditional variance of stock returns often increases when returns are negative, i.e. when the financial leverage of the firm increases. In order to capture the asymmetry in return volatility ("leverage effect"), a new class of models was developed, termed the asymmetric ARCH models. Among the most widely spread asymmetric ARCH, models are the Exponential GARCH (EGARCH), GJR and the Asymmetric Power ARCH (APARCH) model.

One of the earliest and most popular asymmetric ARCH models is the EGARCH model that was proposed by Nelson (1991). The EGARCH $(p, q)$ model is given by

$$
\log \sigma_{t}^{2}=\omega+\sum_{i=1}^{q} \beta_{i} \log \sigma_{t-i}^{2}+\sum_{i=1}^{p} \alpha_{i}\left|\frac{\varepsilon_{t-i}}{\sigma_{t-i}}\right|+\gamma_{i} \frac{\varepsilon_{t-i}}{\sigma_{t-i}}
$$

The conditional variance in the above Nelson's EGARCH model is in the logarithmic form which ensures its non-negativity without the need to impose additional non-negativity constraints. The term $\frac{\varepsilon_{t-i}}{\sigma_{t-i}}$ in the above equation represents the asymmetric effect of shocks. A negative shock leads to higher conditional variance in the following period which is not the case with a positive shock (Poon and Granger, 2003).

A special variation of the $\operatorname{EGARCH}(p, q)$ model is the $\operatorname{EGARCH}(1,1)$ model, which is given by:

$$
\log \sigma_{t}^{2}=\omega+\beta_{1} \log \sigma_{t-1}^{2}+\alpha\left|\frac{\varepsilon_{t-1}}{\sigma_{t-1}}\right|+\gamma \frac{\varepsilon_{t-1}}{\sigma_{t-1}}
$$

For a positive shock $\frac{\varepsilon_{t-1}}{\sigma_{t-1}}>0$, the above equation becomes

$\log \sigma_{t}^{2}=\omega+\beta_{1} \log \sigma_{t-1}^{2}+(\alpha+\gamma) \frac{\varepsilon_{t-1}}{\sigma_{t-1}}$

whereas for a negative shock $\frac{\varepsilon_{t-1}}{\sigma_{t-1}}<0$, the above equation becomes

$$
\log \sigma_{t}^{2}=\omega+\beta_{1} \log \sigma_{t-1}^{2}+(\alpha-\gamma) \frac{\varepsilon_{t-1}}{\sigma_{t-1}}
$$

The exponential nature of the EGARCH model guarantees that the conditional variance is always positive even if the coefficients are negative (Angabini and Wasiuzzaman, 2011). By 
testing the hypothesis that $\gamma=0$, we can determine if there is a leverage effect. If $\gamma \neq 0$, the impact is asymmetric. By inclusion of the parameter $\beta$ in the EGARCH $(1,1)$ model, the persistence of volatility shocks is captured.

The EGARCH model has a number of advantages over the GARCH $(p, q)$ model. The most important one is its logarithmic specification, which allows for relaxation of the positive constraints among the parameters. Another advantage of the EGARCH model is that it incorporates the asymmetries in stock return volatilities. The parameters $\alpha$ and $\gamma$ capture two important asymmetries in conditional variances. If $\gamma<0$ negative shocks increase the volatility more than positive shocks of the same magnitude. Due to the parameter $\alpha$ expected to be positive, large shocks of any sign will comparablearger impact compared to small shocks. Another advantage of the EGARCH model is that it successfully captures the persistence of volatility shocks. Based on these advantages, we apply the EGARCH model for estimating the volatility of the Macedonian stock market.

GARCH-GJR model is another type of asymmetric GARCH models, which was proposed by Glosten, Jagannatahan and Runkle (1993). Its generalized version is given by:

$$
\sigma_{t}^{\delta}=\omega+\sum_{i=1}^{p} \alpha_{i} \varepsilon_{t-i}^{2}+\sum_{j=1}^{q} \beta_{j} \sigma_{t-j}^{2}+\gamma_{i} I_{t-i} \varepsilon_{t-i}^{2}
$$

where $\alpha, \beta$ and $\gamma$ are constant parameters, and $I$ is a dummy variable (indicator function) that takes the value zero (respectively one) when $\varepsilon_{t-i}$ is positive (negative). If $\gamma$ is positive, negative errors are leveraged (negative innovations or bad news has a greater impact than the positive ones). We assume that the parameters of the model are positive and that $\alpha+\beta+\gamma / 2<1$.

Ding, Engle and Granger (1993) introduced the asymmetric power ARCH model called $\operatorname{APACH}(p, q)$. The variance equation of $\operatorname{APACH}(p, q)$ can be written as

$$
\sigma_{t}^{\delta}=\omega+\sum_{i=1}^{p}\left(\alpha_{i}\left|\varepsilon_{t-i}\right|-\gamma_{i} \varepsilon_{t-i}\right)^{\delta}+\sum_{j=1}^{q} \beta_{j} \sigma_{t-j}^{\delta}
$$

where $\omega>0, \delta>0, \alpha_{i} \geq 0,-1<\gamma_{i}<1, i=1, \ldots, p, \beta_{j} \geq 0, j=1, \ldots q$.

This model changes the second order of the error term into a more flexible varying exponent with an asymmetric coefficient which allows for the leverage effect.

In our paper we estimate conditional volatility using the probability distributions that are available in the GARCH package: the normal and the Student t-distribution. Engle (1982), who introduced the ARCH model, assumed that asset returns follow a normal distribution. However, it is usually referred in the literature that asset returns distribution are not normally distributed, so that the normality assumption could cause significant bias in VaR estimation and could underestimate the volatility (Mandelbrot, 1963). A number of authors (Vilasuso, 2002; Brooks and Persand, 2000) evidenced that standard GARCH models with normal empirical distributions have inferior forecasting performance compared to models that reflect skewness and kurtosis in innovations. To capture the excess kurtosis of financial asset returns, Bollerslev (1987) introduced the GARCH model with a standardized Student's $t$ distribution with $v>2$ degrees of freedom. 
After describing the properties of selected GARCH family models, we turn now to the question how we can estimate GARCH models when the only variable on which there are available data is the data on asset returns. The common methodology used for GARCH estimation is maximum likelihood assuming i.i.d. innovations.

The parameters of the GARCH model can be found by maximizing the objective loglikelihood function:

$$
\ln L(\theta)=-\frac{1}{2} \sum_{t=1}^{n}\left[\ln (2 \pi)+\ln \left(\sigma_{t}^{2}(\theta)\right)+z_{t}^{2}(\theta)\right]
$$

where $\theta$ is the vector of parameters $\left(\mu, \omega, \alpha_{i}, \beta_{j}\right)$ estimated that maximize the objective function $\ln L(\theta) ; z_{t}$ represents the standardized residual calculated as $\frac{\Delta y_{t}-\mu}{\sqrt{\sigma_{t}^{2}}}$. The other symbols have the same meaning as above described.

Maximum likelihood estimates of the parameters can be obtained via nonlinear least squares using Marquardt's algorithm. Engle (2001) suggests an even simpler answer to use software such as EViews, SAS, GAUSS, TSP, Matlab, RATS and others. In our paper we estimate the GARCH family models using the econometric computer package EViews 6.

\section{Data and descriptive statistics}

In this paper we examine the relative performance of selected symmetric GARCH models, such as, the GARCH $(1,1)$ model with normal and Student's t-distribution and the GARCH-M model and the asymmetric GARCH models, such as, the EGARCH $(1,1)$ with normal and Student's t-distribution and the APARCH $(1,1)$, model with regard to evaluation and forecasting $\mathrm{VaR}$ in the Macedonian stock exchange under crisis times. For emerging economies, such as Macedonia, a significant problem for a serious and statistically significant analysis is the short histories of their market economies and active trading in financial markets (Andjelic et al., 2010). Because of the short time series of individual stock returns, Andjelic et al. (2010) suggest analyzing the stock indices of these countries. The stock indices represent a portfolio of selected stocks from an individual stock market. Thus data used in this paper are the daily return series of the Macedonian stock index $-\mathrm{MBI} 10 . \mathrm{MBI} 10$ is a price index weighted by market capitalization and consists of up to 10 listed ordinary shares, chosen by the Macedonian Stock Exchange Index Commission. The index was introduced with a base level of 1.000 on the $30^{\text {th }}$ December 2004.

The data for our study are collected from the official website of the Macedonian stock exchange http://www.mse.org.mk. VaR figures are calculated for a one-day ahead horizon with $95 \%$ and $99 \%$ confidence levels (coverage of the market risk). The data span the period from the $4^{\text {th }}$ of January 2005 to the $31^{\text {st }}$ October 2011 and comprise 1638 observations. The daily stock return is calculated as $r_{t}=\log \left(\frac{x_{t}}{x_{t-1}}\right) \times 100$

where $x_{t}$ is the daily closing value of the stock market on day $t$. In this paper we use the daily closing values of the Macedonian stock market.

The daily closing values of the Macedonian stock index MBI-10 and its returns are displayed in Figure 1 and Figure 2, respectively.

As it can be seen from Figure 1 the closing values of MBI-10 show a random walk. From Figure 2 it is evident that the daily returns are stationary. 


\section{Figure 1}

Daily Closing Values of the Macedonian Stock Index MBI-10 in the Period from the $4^{\text {th }}$ January 2005 to the $31^{\text {st }}$ October 2011

VALUE

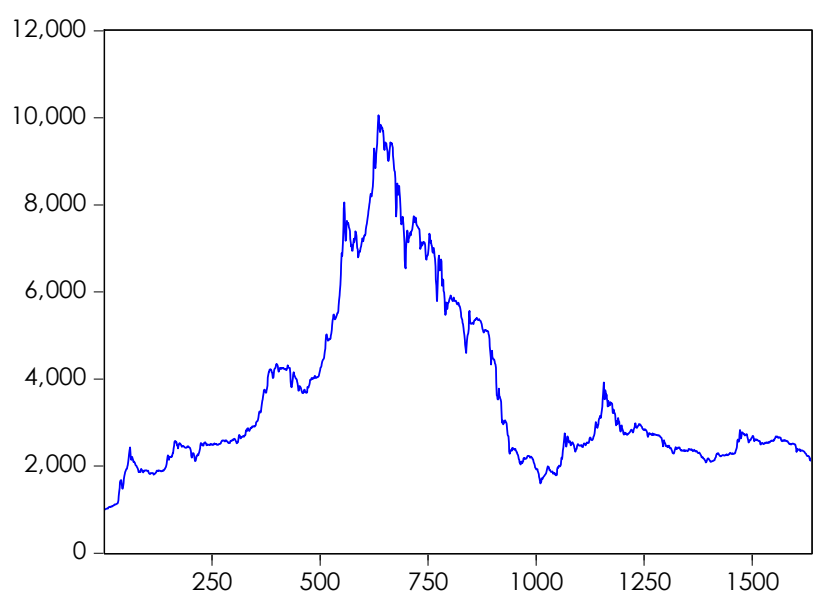

Source: The Official Web Site of the Macedonian Stock Exchange http://www.mse.org.mk

\section{Figure 2}

Daily Stock Returns of the Macedonian Stock Index MBI-10 in the Period from the $4^{\text {th }}$ January 2005 to the $31^{\text {st }}$ October 2011

\section{RETURN100}

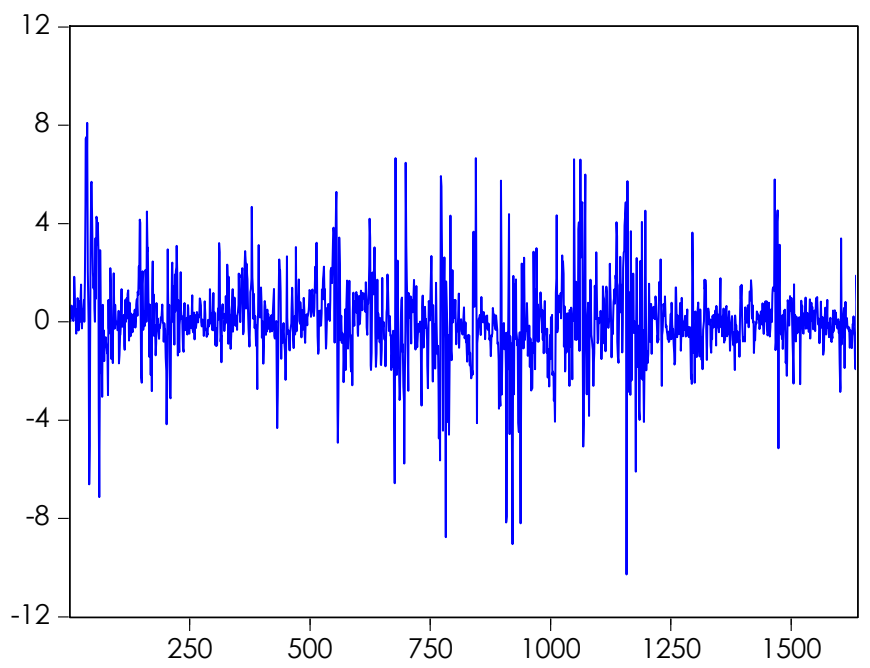

Source: The Official Web Site of the Macedonian Stock Exchange http://www.mse.org.mk

The return data is tested for autocorrelation both in log returns as well as in squared log returns (see Table 1 and Table 2). We test the presence of autocorrelation in log returns using the ACF, PACF and the mean adjusted Ljung-Box Q-statistics, and autocorrelation in squared log returns is tested by ACF, PACF, Ljung-Box Q-statistic and Engle's ARCH test (Zikovic, 2007). If we detect the presence of autocorrelation in log returns, we can remove it by fitting the simplest plausible ARMA $(p, q)$ model to the data. On the other hand, if autocorrelation is detected in the squared log returns, heteroskedasticity from the series could be removed by fitting the simplest plausible GARCH model to the ARMA filtered data (Zikovic, 2007). 
Table 1

Correlogram of Daily Stock Returns of the Macedonian Stock Index MBI-10 in the Period from the $4^{\text {th }}$ January 2005 to the $31^{\text {st }}$ October 2011

\begin{tabular}{|c|c|c|c|c|}
\hline Lag & $A C$ & PAC & Q-Stat & Prob \\
\hline 1 & 0.463 & 0.463 & 351.060 & 0.000 \\
\hline 2 & 0.097 & -0.148 & 366.630 & 0.000 \\
\hline 3 & 0.021 & 0.050 & 367.370 & 0.000 \\
\hline 4 & 0.005 & -0.016 & 367.410 & 0.000 \\
\hline 5 & -0.006 & -0.004 & 367.470 & 0.000 \\
\hline 6 & 0.043 & 0.064 & 370.500 & 0.000 \\
\hline 7 & 0.029 & -0.028 & 371.910 & 0.000 \\
\hline 8 & 0.038 & 0.047 & 374.270 & 0.000 \\
\hline 9 & 0.080 & 0.058 & 384.730 & 0.000 \\
\hline 10 & 0.091 & 0.033 & 398.430 & 0.000 \\
\hline 11 & 0.104 & 0.066 & 416.300 & 0.000 \\
\hline 12 & 0.127 & 0.066 & 442.960 & 0.000 \\
\hline 13 & 0.088 & 0.003 & 455.830 & 0.000 \\
\hline 14 & 0.035 & -0.001 & 457.890 & 0.000 \\
\hline 15 & 0.037 & 0.031 & 460.170 & 0.000 \\
\hline 16 & 0.070 & 0.051 & 468.310 & 0.000 \\
\hline 17 & 0.059 & 0.002 & 474.120 & 0.000 \\
\hline 18 & 0.027 & -0.013 & 475.300 & 0.000 \\
\hline 19 & 0.045 & 0.044 & 478.710 & 0.000 \\
\hline 20 & 0.020 & -0.037 & 479.400 & 0.000 \\
\hline 21 & 0.032 & 0.035 & 481.100 & 0.000 \\
\hline 22 & 0.085 & 0.055 & 493.220 & 0.000 \\
\hline 23 & 0.052 & -0.039 & 497.720 & 0.000 \\
\hline 24 & -0.009 & -0.031 & 497.850 & 0.000 \\
\hline 25 & 0.025 & 0.042 & 498.850 & 0.000 \\
\hline 26 & 0.042 & 0.004 & 501.860 & 0.000 \\
\hline 27 & 0.030 & -0.001 & 503.350 & 0.000 \\
\hline 28 & 0.018 & -0.019 & 503.880 & 0.000 \\
\hline 29 & 0.025 & 0.018 & 504.920 & 0.000 \\
\hline 30 & 0.029 & 0.012 & 506.280 & 0.000 \\
\hline
\end{tabular}

Source: Author's Calculations

The Ljung and Box $Q$ statistics on the $1^{\text {st }}, 10^{\text {th }}$ and $20^{\text {th }}$ lags of the sample autocorrelations functions of the return series indicate significant serial correlation. ARCH effect is present in all time series in accordance with the Ljung-Box $Q$ statistics of the stock indices' squared returns on the $30^{\text {th }}$ lags and Engle's ARCH test on the $10^{\text {th }}$ lags.

The empirical distribution of the daily return rates deviates from the normal distribution. Namely, the Macedonian stock market returns display significant negative skewness as well as large kurtosis, suggesting that the return distribution is a fat-tailed one. Skewness and kurtosis values satisfy the Jarque-Bera tests for normality which is rejected. The Q-Q plot, which displays the quantiles of return data series against the quantiles of the normal distribution (see Figure 3), shows that there is a low degree of fit of the empirical distribution to the normal one. 
Table 2

Correlogram of Squared Daily Stock Returns of the Macedonian Stock index MBI-10 in the Period from the $4^{\text {th }}$ January 2005 to the $31^{\text {st }}$ October 2011

\begin{tabular}{|c|c|c|c|c|}
\hline Lag & $A C$ & PAC & Q-Stat & Prob \\
\hline 1 & 0.330 & 0.330 & 178.970 & 0.000 \\
\hline 2 & 0.254 & 0.162 & 284.550 & 0.000 \\
\hline 3 & 0.201 & 0.089 & 350.740 & 0.000 \\
\hline 4 & 0.207 & 0.105 & 421.220 & 0.000 \\
\hline 5 & 0.123 & -0.005 & 446.230 & 0.000 \\
\hline 6 & 0.172 & 0.091 & 495.050 & 0.000 \\
\hline 7 & 0.125 & 0.016 & 520.680 & 0.000 \\
\hline 8 & 0.092 & -0.008 & 534.560 & 0.000 \\
\hline 9 & 0.097 & 0.030 & 550.120 & 0.000 \\
\hline 10 & 0.141 & 0.072 & 583.050 & 0.000 \\
\hline 11 & 0.083 & -0.010 & 594.320 & 0.000 \\
\hline 12 & 0.173 & 0.117 & 643.600 & 0.000 \\
\hline 13 & 0.149 & 0.041 & 680.110 & 0.000 \\
\hline 14 & 0.059 & -0.070 & 685.780 & 0.000 \\
\hline 15 & 0.033 & -0.035 & 687.570 & 0.000 \\
\hline 16 & 0.065 & 0.006 & 694.620 & 0.000 \\
\hline 17 & 0.115 & 0.084 & 716.640 & 0.000 \\
\hline 18 & 0.043 & -0.040 & 719.760 & 0.000 \\
\hline 19 & 0.072 & 0.017 & 728.300 & 0.000 \\
\hline 20 & 0.055 & 0.005 & 733.410 & 0.000 \\
\hline 21 & 0.071 & 0.030 & 741.800 & 0.000 \\
\hline 22 & 0.037 & -0.029 & 744.090 & 0.000 \\
\hline 23 & 0.074 & 0.025 & 753.230 & 0.000 \\
\hline 24 & 0.064 & 0.018 & 760.150 & 0.000 \\
\hline 25 & 0.058 & -0.005 & 765.670 & 0.000 \\
\hline 26 & 0.032 & -0.012 & 767.380 & 0.000 \\
\hline 27 & 0.039 & 0.005 & 769.870 & 0.000 \\
\hline 28 & 0.023 & 0.003 & 770.730 & 0.000 \\
\hline 29 & 0.049 & -0.000 & 774.710 & 0.000 \\
\hline 30 & 0.020 & -0.023 & 775.350 & 0.000 \\
\hline
\end{tabular}

Source: Author's Calculations

\section{Figure 3}

Q-Q Plot of Daily Stock Returns of the Macedonian Stock index MBI-10 in the Period from the $4^{\text {th }}$ January 2005 to the $31^{\text {st }}$ October 2011

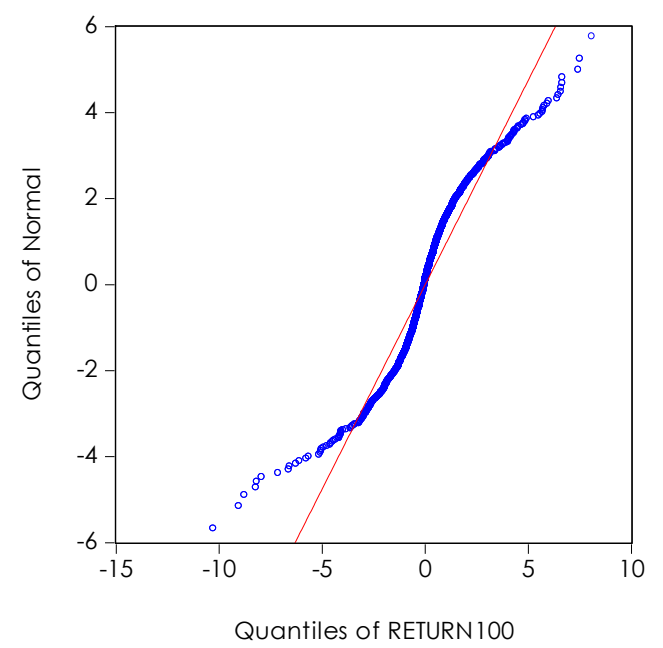

Source: Author's Calculations 
The summary of the descriptive statistics for the daily logarithmic stock index returns of the MBI-10 is presented in Table 3.

Table 3

Summary Descriptive Statistics for the Daily Returns of the Macedonian Stock Index MBI-10 for the Period 04.01.2005-31.10.2011

\begin{tabular}{|l|r|}
\hline Descriptive statistics & 0.0477 \\
\hline Mean & 0.0000 \\
\hline Median & 8.0897 \\
\hline Maximum & -10.2831 \\
\hline Minimum & 1.6698 \\
\hline Std. Dev. & -0.1425 \\
\hline Skewness & 8.6211 \\
\hline Kurtosis & \\
\hline Normality tests & 2160.6960 \\
\hline Jarque-Berra statistic & 0.0000 \\
\hline P-value & 0.1058 \\
\hline Lilliefors & 0.0000 \\
\hline P-value & 398.4300 \\
\hline ARCH tests & 506.2800 \\
\hline Q2(10) & -24.3180 \\
\hline Q2(30) & -23.8274 \\
\hline Unit root tests & \\
\hline ADF & \\
\hline P-P &
\end{tabular}

Source: Author's Calculations

\section{Empirical results}

Since there are ARCH effects in the stock return data, we can proceed with estimation of GARCH models.

We estimate the following symmetric GARCH models: the GARCH $(1,1)$ model with normal and Student's t-distribution and the GARCH-M model as well as the following asymmetric GARCH models: the EGARCH $(1,1)$ model with normal and Student's t-distribution distribution, the GARCH-GJR model and the APARCH model.

The parameters of the estimated models and the residual tests of autocorrelation, normality and conditional heteroskedasticity are given in Table 4.

Once we estimated the symmetric and asymmetric GARCH models, we conduct the ARCH-LM test proposed by Engle (1982) in order to detect if there are any ARCH effects in the residuals left and to prove that the above estimated GARCH-type models successfully capture the persistence of volatility shocks. Table 4 exhibits the p-values of LM test and the standardized squared residuals. To test whether our GARCH family models were correctly specified, we perform diagnostic checks. The results of these checks for all tested models show that the Q-statistics for the standardized squared residuals are insignificant with high $\mathrm{p}$ values, which supports the conclusion that the above specified GARCH models adequately capture the serial correlation in conditional means and variances.

We have to note that there are no ARMA components in the estimated models. The parameters are estimated using BHHH algorithm (Berndt, et al., 1974).

According to the results of the sign and size bias test proposed by Engle and Ng "(Engle and $\mathrm{Ng}, 1993$ )", there is a strong evidence of asymmetric effects, which makes the use of asymmetric GARCH models justified (see Table 5 and Table 6). 
Table 4

Estimated GARCH Models for the Daily Returns of the Macedonian Stock Index MBI-10

\begin{tabular}{|l|r|r|r|r|r|r|r|}
\hline & $\begin{array}{l}\text { GARCH } \\
\text { normal } \\
\text { distribu- } \\
\text { tion }\end{array}$ & $\begin{array}{l}\text { GARCH } \\
\text { t-distri- } \\
\text { bution }\end{array}$ & $\begin{array}{l}\text { EGARCH } \\
\text { normal } \\
\text { distribution }\end{array}$ & $\begin{array}{l}\text { EGARCH } \\
\text { t-distri- } \\
\text { bution }\end{array}$ & $\begin{array}{l}\text { GARCH- } \\
\text { GJR }\end{array}$ & APARCH & GARCH-M \\
\hline$\alpha_{0}$ & 0.0877 & 0.1490 & -0.3494 & -0.4546 & 0.0879 & 0.0864 & 0.0882 \\
\hline$\alpha_{1}$ & 0.3416 & 0.6160 & 0.5313 & 0.7069 & 0.3165 & 0.3497 & 0.3436 \\
\hline$\beta_{1}$ & 0.6781 & 0.4964 & 0.9264 & 0.8947 & 0.6762 & 0.6595 & 0.6764 \\
\hline$\gamma$ & & & -0.0263 & -0.0253 & 0.0579 & & \\
\hline$\omega$ & & & & & & 0.0388 & \\
\hline$\delta$ & & & & & & 2.2846 & \\
\hline $\begin{array}{l}\text { Skew- } \\
\text { ness }\end{array}$ & -0.0888 & -0.3798 & -0.0984 & -0.3259 & -0.0568 & -0.0569 & -0.0831 \\
\hline Kurtosis & 6.3992 & 9.0423 & 6.6122 & 7.9355 & 6.3753 & 6.3002 & 6.4114 \\
\hline & & & & & & & 7430 \\
\hline $\begin{array}{l}\text { Jarque- } \\
\text { Bera }\end{array}$ & 789.7841 & 2528.1160 & 892.0988 & 1689.4490 & 777.4950 & 743.3075 & 795.2002 \\
\hline $\begin{array}{l}\text { ARCH } \\
\text { (10) }\end{array}$ & 13.5711 & 9.1340 & 11.5987 & 8.4399 & 12.7535 & 12.3460 & 12.9104 \\
\hline prob & 0.1935 & 0.5194 & 0.3128 & 0.5859 & 0.2378 & 0.2626 & 0.2287 \\
\hline & & & & & & & \\
\hline Q2 30) & 26.3290 & 17.7080 & 26.2320 & 25.2430 & 25.9550 & 25.3650 & 25.4930 \\
\hline prob & 0.6580 & 0.9630 & 0.6630 & 0.7130 & 0.6770 & 0.7070 & 0.7010 \\
\hline
\end{tabular}

Source: Author's Calculations

Table 5

Engle and $\mathrm{Ng}$ Joint Test for Sign and Size Bias

\begin{tabular}{|l|r|r|r|r|}
\hline Variable & Coefficient & Std. Error & \multicolumn{1}{l|}{ t-Statistic } & Prob. \\
\hline C & 2.0285 & 0.2772 & 7.3168 & 0.0000 \\
\hline S & -0.0278 & 0.3825 & -0.0726 & 0.9421 \\
\hline S*RESIDUALS(-1) & -1.2926 & 0.1624 & -7.9576 & 0.0000 \\
\hline S2*RESIDUALS(-1) & 1.6506 & 0.1611 & 10.2447 & 0.0000 \\
\hline$R^{2}$ & 0.0940 & Mean dependent var & 2.7908 \\
\hline Adjusted R & 0.0923 & S.D. dependent var & 7.6962 \\
\hline S.E. of regression & 7.3324 & \multicolumn{2}{|c|}{ Akaike info criterion } & 6.8249 \\
\hline Sum squared resid & 87688.1600 & Schwarz criterion & 6.8381 \\
\hline Log likelihood & -5575.3670 & \multicolumn{4}{|l}{ Hannan-Quinn criter. } & 6.8298 \\
\hline F-statistic & 56.3969 & Durbin-Watson stat & 1.6922 \\
\hline Prob(F-statistic) & 0.0000 & \multicolumn{4}{|l}{}
\end{tabular}

Source: Author's Calculations

To capture the dynamic process of data generating and the presence of the "leverage effect" in the MBI-10 index, we use the nonlinear asymmetric models EGARCH and GJRGARCH model. The coefficient $\gamma$ in the case of GJR-GARCH is statistically significant at level of significance of $7 \%$ implying that there is an asymmetry. On the other hand, Its positive value indicates presence of the "leverage effect". The coefficient $\gamma$ in the EGARCH model is significantly different from zero, which indicates presence of asymmetry. The value of $\gamma$ which is less than zero, implies presence of the "leverage effect".

We have forecasted future return rate and volatility for one-day-ahead based on the estimated parameters of the models. These forecasted values are necessary for the estimation of VaR. The estimated values of the VaR parameters at risk for one-day-ahead as well as the probabilities of $95 \%$ and $99 \%$ are exhibited in Table 7. 
Table 6

Engle and $\mathrm{Ng}$ Joint Test Statistic

\begin{tabular}{|c|c|c|c|}
\hline \multicolumn{4}{|l|}{ Wald Test: } \\
\hline \multicolumn{4}{|c|}{ Equation: EQENGLENGJOINT } \\
\hline Test Statistic & Value & $\mathrm{df}$ & Probability \\
\hline F-statistic & 56.3969 & $(3,1631)$ & 0.0000 \\
\hline Chi-square & 169.1908 & 3 & 0.0000 \\
\hline \multicolumn{4}{|c|}{ Null Hypothesis Summary: } \\
\hline \multicolumn{2}{|c|}{ Normalized Restriction ( $=0$ ) } & Value & Std. Err. \\
\hline \multicolumn{2}{|l|}{$C(2)$} & -0.0278 & 0.3825 \\
\hline \multicolumn{2}{|l|}{$C(3)$} & -1.2926 & 0.1624 \\
\hline \multicolumn{2}{|l|}{$C(4)$} & 1.6506 & 0.1611 \\
\hline
\end{tabular}

Source: Author's Calculations

Table 7

Econometric Estimation of the Parameters of VaR for One-Day-Ahead Period

\begin{tabular}{|c|c|c|c|c|c|c|c|}
\hline Model & 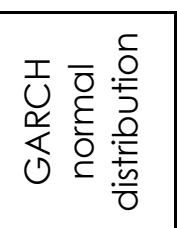 & 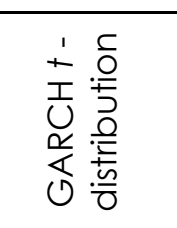 & 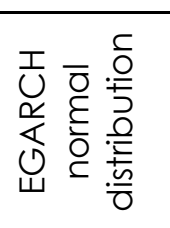 & 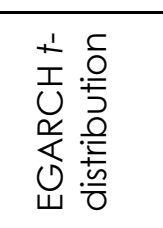 & 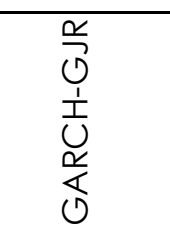 & $\begin{array}{l}\frac{T}{0} \\
\frac{\alpha}{4} \\
\frac{\alpha}{\alpha}\end{array}$ & 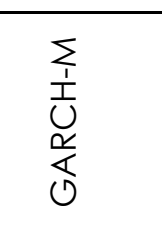 \\
\hline $\begin{array}{l}\text { Forecasted } \\
\text { return }\end{array}$ & 0.0215 & 0.0013 & 0.0166 & -0.0115 & 0.0107 & 0.0098 & 0.0721 \\
\hline $\begin{array}{l}\text { Forecasted } \\
\text { conditional } \\
\text { variance }\end{array}$ & 1.4342 & 1.2740 & 0.9720 & 0.8959 & 1.4166 & 1.1982 & 1.4027 \\
\hline VaR 0.95 & $-1.9545 \%$ & $-1.8611 \%$ & $-1.6102 \%$ & $-1.5733 \%$ & $-1.9532 \%$ & $-1.7963 \%$ & $-1.8821 \%$ \\
\hline Var 0.99 & $-3.0683 \%$ & $-2.9109 \%$ & $-2.5271 \%$ & $-2.4535 \%$ & $-3.0601 \%$ & $-2.8143 \%$ & $-2.9835 \%$ \\
\hline
\end{tabular}

Source: Author's Calculations

Please note that the estimated VaR values obtained with the GARCH approach are negative. The negative sign is usually ignored since we assume that we are talking about indicator of loss.

With probability of $95 \%$ we can expect that the maximum loss due to having stocks in amount of MKD 10,000 in the Macedonian stock exchange is around MKD 195 in a one day period.

\section{Discussion and conclusion}

This paper tests the relative performance of a range of symmetric and asymmetric GARCH family models based on two residual distributions (normal and Student's t-distribution) in terms of their ability of estimating VaR in the Macedonian stock market.

Using the daily returns of the Macedonian stock index-MBI 10 we have tested the relative performance of the GARCH $(1,1)$ model with normal and Student's t-distribution, the GARCH$M$ model, the EGARCH $(1,1)$ with normal and Student's t-distribution and the APARCH $(1,1)$ model in the period from the $4^{\text {th }}$ January 2005 to the $31^{\text {st }}$ October 2011 , a sufficiently long period which includes tranquil as well as crisis years.

Descriptive statistics for the MBI-10 show presence of skewness and kurtosis. The results of the conducted ARCH-LM test point out significant presence of ARCH effect in the residuals as well as volatility clustering effect. Standardized residuals and standardized residuals squared were white noise.

We have shown that the econometric estimation of VaR can be related to the chosen GARCH model. Therefore a first step in estimation of the parameters of $V a R$ is a detailed specification analysis of the potential models.

The empirical results have indicated that the most adequate GARCH models for estimating and forecasting VaR in the Macedonian stock market are the EGARCH model with Student's 
t-distribution, the EGARCH model with normal distribution and the GARCH-GJR model which are robust with regard to estimation.

The findings reported in this paper bear very important implications regarding VaR estimation in turbulent times, market timing, portfolio selection etc. that have to be addressed by investors and other risk managers operating in emerging capital markets.

However, the main limitation of our study is that in our empirical research we have focused solely on the Macedonian stock exchange and therefore the obtained findings can not be generalized to other emerging financial markets. In the future research we will attempt to overcome this limitation by using a wider sample of emerging markets - the EU candidate and potential candidate countries which are attractive destinations for foreign investors.

Another issue for future research agenda is the inclusion of other asymmetric GARCH-type models and testing and comparing their predictive performance.

\section{References}

1. Andjelić, G., Djaković, V., Radišić, S. (2010), "Application of VaR in Emerging markets: A Case of Selected Central and Eastern European Countries", African Journal of Business Management, Vol. 4, No. 17, pp. 3666-3680.

2. Angabini, A., Wasiuzzaman, S. (2011), "GARCH Models and the Financial Crisis-A Study of the Malaysian Stock Market", The International Journal of Applied Economics and Finance, Vol. 5, No. 3, pp. 226-236.

3. Angelidis, T., Degiannakis, S. (2005), "Modeling Risk for Long and Short Trading Positions", The Journal of Risk Finance, Vol. 6, No. 3, pp. $226-238$.

4. Bae, K., Karolyi, G. A. (1994), "Good News, Bad News and International Spillovers of Stock Return Volatility between Japan and the U.S.", Pacific-Basin Finance Journal, Vol. 2, No. 4, pp. 405-438.

5. Balaban, E. (2002), "Comparative Forecasting Performance of Symmetric and Asymmetric Conditional Volatility Models of an Exchange Rate", Working Paper, University of Edinburgh Center for Financial Markets Research, Edinburgh, pp. 1-14.

6. Bao, Y., Lee, T., Saltoglu, B. (2006), "Evaluating Predictive Performance of Value-at-Risk Models in Emerging Markets: A Reality Check", Journal of Forecasting, Vol. 25, No. 2, pp. 101-128.

7. Batten, J. A., Szilagyi, P. G. (2011), "The Impact of the Global Financial Crisis on Emerging Financial Markets: An Introduction", in Batten, J. A., Szilagyi P. G. (eds.), The Impact of the Global Financial Crisis on Emerging Financial Markets (Contemporary Studies in Economic and Financial Analysis 93), Emerald Group Publishing Limited, Bingley, pp. 3-17.

8. Bekaert, G., Harvey, C. R. (1995), "Time-Varying World Market Integration", Journal of Finance, Vol. 50, No. 2, pp. 403-444.

9. Bekaert, G., Guojun, W. (2000), "Asymmetric Volatility and Risk in Equity Markets", The Review of Financial Studies, Vol. 13, No. 1, pp. 1-42.

10. Benaković, D., Posedel, P. (2010), "Do Macroeconomic Factors Matter for Stock Returns? Evidence from Estimating a Multifactor Model on the Croatian Market", Business Systems Research Journal, Vol. 1, No.1-2, pp. 39-46.

11. Berndt, E., Hall, B., Hall, R., Hausman, J. (1974), "Estimation and Inference in Nonlinear Structural Models", Annals of Economic and Social Measurement, Vol. 3, pp. 653-665.

12. Black, F. (1976), "Studies of Stock Price Volatility Changes", in Proceeding of the 1976 Meetings of the Business and Economic Statistics Section, American Statistical Association, pp. 177-181.

13. Braun, P. A., Nelson, D. B., Sunier, A. M. (1995), "Good News, Bad News, Volatility, and Betas", Journal of Finance, Vol. 50, No. 5, pp. 1575-1603.

14. Bollerslev, T. (1987), "Conditionally Heteroskedastic Time Series Model for Speculative Prices and Rates of Return", Review of Economics and Statistics, Vol. 69, No. 3, pp. 542-547.

15. Brooks, C. (2008). Introductory Econometrics for Finance, 2nd ed., Cambridge, Cambridge University Press.

16. Bollerslev, T., Chou, R. Y., Kroner, K. F. (1992), "ARCH Modeling in Finance: A Review of the Theory and Empirical Evidence", Journal of Econometrics, Vol. 52, No. 1-2, pp. 5-59. 
17. Brooks, C., Persand G. (2000), "A Word of Caution on Calculating Market Based Minimum Capital Risk Requirements", Journal of Banking and Finance, Vol. 24, No. 10, pp. 1557-1574.

18. Campbell, J. Y., Hentshel, L. (1992), "No News is Good News: An Asymmetric Model of Changing Volatility in Stock Returns", Journal of Financial Economics, Vol. 31, No. 3, pp. 281-318.

19. Cheung, Y., Ng, L. (1992), "Stock Price Dynamics and Firm Size: An Empirical Investigation", Journal of Finance, Vol. 47, No. 5, pp. 1985-1997.

20. Christie, A. A. (1982), "The Stochastic Behavior of Common Stock Variances - Value, Leverage and Interest Rate Effects", Journal of Financial Economics, Vol. 10, No. 4, pp. 407-432.

21. Curto, J. D., Pinto, J. C., Tavares, G. N. (2009), "Modelling Stock Markets' Volatility Using GARCH Models with Normal, Student's $t$ and Stable Paretian Distributions", Statistical Papers, Vol. 50, No. 2, pp. 311-321.

22. Da Silva, A., Beatriz, V., de Melo Mendes, B. (2003), "Value-at-Risk and Extreme Returns in Asian Stock markets", International Journal of Business, Vol. 8, No. 1, pp. 17-40.

23. Dimitrakopoulos, D. N., Kavussanos M. G. and Spyrou, S. I. (2010), "Value at Risk Models for Volatile Emerging Markets Equity Portfolios", The Quarterly Review of Economics and Finance, Vol. 50, No. 4, pp. 515-526.

24. Ding, Z., Engle, R., Granger C. (1993), "A Long Memory Property of Stock Market Returns and A New Model", Journal of Empirical Finance, Vol. 1, No. 1, pp. 83-106.

25. Dufee, G. R. (1995), "Stock Returns and Volatility: A Firm Level Analysis", Journal of Financial Economics, Vol. 37, No. 3, pp. 399-420.

26. Engle, R. F. (1982), "Autoregressive Conditional Heteroscedasticity with Estimates of the Variance of UK Inflation", Econometrica, Vol. 50, No. 4, pp. 987-1008.

27. Engle, R. F. (2001), "GARCH 101: The Use of ARCH/GARCH Models in Applied Econometrics", Journal of Economic Perspectives, Vol. 15, No. 4, pp. 157-168.

28. Engle, R. F., Lilien, D. M., Robbins, R. P. (1987), "Estimating Time Varying Risk Premia in the Term Structure: The ARCH-M Model", Econometrica, Vol. 55, No. 2, pp. 391-407.

29. Engle, R. F., Ng, V. K. (1993), "Measuring and Testing the Impact of News on Volatility", Journal of Finance, Vol. 48, No. 5, pp. 1749-1778.

30. Franses, P. H., Van Dijk, D. (1996), "Forecasting Stock Market Volatility Using (Non-Linear) GARCH Models", Journal of Forecasting, Vol. 15, No. 3, pp. 229-235.

31. French, K., Schwert, G., Stambaugh, R. (1987), "Expected Stock Returns and Volatility", Journal of Financial Economics, Vol. 19, No. 1, pp. 3-29.

32. Glosten, L. R., Jagannathan, R., Runkle, D. E. (1993), "On the Relation Between the Expected Value and the Volatility of the Nominal Excess Return on Stocks", Journal of Finance, Vol. 48, No. 5, pp. 1779-1801.

33. Gokcan, S. (2000), "Forecasting Volatility of Emerging Stock Markets: Linear Versus NonLinear GARCH Models", Journal of Forecasting, Vol. 19, No. 6, pp. 499-504.

34. Hagerud, G. E. (1997), "Modelling Nordic Stock Returns with Asymmetric GARCH models", Working Paper Series in Economics and Finance, Vol. 164, Stockholm School of Economics, Stockholm, pp. 1-26.

35. Hien, M. T. T. (2008), "Modelling and Forecasting Volatility by GARCH-Type Models: The Case of Vietnam Stock Exchange", A Dissertation Presented in Part Consideration for the Degree of MA. Finance and Investment, pp. 1-97, available at: http://edissertations.nottingham.ac.uk/2017/1/08MAlixhm7.pdf (9 April 2012).

36. Jorion, P. (2007). Value at Risk: The New Benchmark for Managing Financial Risk, 3rd ed., New York, McGraw-Hill.

37. Kovacic, Z. (2007), "Forecasting Volatility: Evidence from the Macedonian Stock Exchange" Unpublished MPRA Paper No. 5319, pp. 1-44, available at: http://mpra.ub.unimuenchen.de/5319/1/MPRA_paper_5319.pdf (15 January 2012).

38. Macedonian stock exchange, available at: http://www.mse.org.mk (5 December 2011).

39. Magnusson, G., Andonov, S. (2002), "Basel Capital Adequacy Ratio and the Iceland Banking Sector: Quantitative Impact, Structural Changes and Optimality Considerations", IOES Working Paper Series, W02:05, pp. 1-51, Institute of Economic Studies, Reykjavik, May 2002. 
40. Mandelbrot, B. (1963), "The Variation of Certain Speculative Prices", Journal of Business, Vol. 36, No. 4, pp. 349-419.

41. McMillan, D. G., Speight, A. E. H. (2007), "Value-at-Risk in Emerging Equity Markets: Comparative Evidence for Symmetric, Asymmetric and Long-Memory GARCH Models", International Review of Finance, Vol. 7, No. 1-2, pp. 1-19.

42. Nelson, D. B. (1991), "Conditional Heteroskedasticity in Asset Returns: A New Approach", Econometrica, Vol. 59, No. 2, pp. 347-370.

43. Ng, A. (2000), "Volatility Spillover Effects from Japan and the US to the Pacific-Basin", Journal of Monetary Economics, Vol. 19, No. 2, pp. 207-233.

44. Pagan, A. R., Schwert, G. W. (1990), "Alternative Models for Conditional Stock Volatility", Journal of Econometrics, Vol. 45, No. 1-2, pp. 267-290.

45. Parrondo, J. M. R. (1997), "Calculation of the Value at Risk in Emerging Markets", Working Paper, Universidad Complutense de Madrid, Madrid, pp. 1-38.

46. Poon, S., Granger, C. W. J. (2003), "Forecasting Volatility in Financial Markets, A Review", Journal of Economic Literature, Vol. 41, No. 2, pp. 478-539.

47. Schwert, G. W. (1990), "Stock Volatility and the Crash of '87", Review of Financial Studies, Vol. 3, No. 1, pp. 77-102.

48. Valentinyi-Endresz, M. (2004), "Structural Breaks and Financial Risk Management", Magyar Nemzeti Bank, Working paper, No. 2004/11, Budapest, pp. 1-60,

49. Vilasuso, J. (2002), "Forecasting Exchange Rate Volatility", Economics Letters, Vol. 76, No. 1, pp. 59-64.

50. Zikovic, S. (2007), "Measuring Market Risk in EU New Member States", available at: http://www.hnb.hr/dub-konf/13-konferencija/zivkovic.pdf (12 December 2011).

51. Zikovic, S., Aktan, B. (2009), "Global Financial Crisis and VAR Performance in Emerging Markets: A Case of EU Candidate States - Turkey and Croatia", Journal of Economics and Business - Proceedings of Rijeka Faculty of Economics, Vol. 27, No. 1, pp. 149-170.

52. Zikovic, S., Bezic, H. (2006), "Is Historical Simulation Appropriate for Measuring Market Risk? A Case of Countries Candidates for EU accession", in Proceedings of the CEDIMES conference, Ohrid, Macedonia, 23-27th March, pp. 1-20.

53. Zikovic, S., Filler, R. K. (2009), "Hybrid Historical Simulation VAR and ES: Performance in Developed and Emerging Markets", CESifo Working paper Series, No. 2820, pp. 1-39, available at: http://www.cesifo-group.de/portal/page/portal/DocBase_Content/WP/WPCESifo_Working_Papers/wp-cesifo-2009/wp-cesifo-2009-10/cesifol_wp2820.pdf December 2011).

\section{About the author}

Vesna Bucevska, Ph.D. was born on the 18th February 1971 in Skopje. She is a full-time professor at the Faculty of Economics in Skopje where she teaches Econometrics, Econometric Theory, Advanced Econometrics, Financial Econometrics and Statistical Quality Control. Her main research areas are statistics, econometrics, financial econometrics and statistical quality control. In these areas she published five textbooks: Econometrics with Application in EViews (with CD), 2009, Econometrics with Application in EViews (with CD), 2008 (in English) Econometrics, 2004, Econometrics - Practice book with key, 2003 and Statistics for Business and Economics-Practice book with key, (in co-authorship) and 70 research papers in academic journals. Author can be reached at vesna@eccf.ukim.edu.mk 